\title{
FAKTOR-FAKTOR YANG MEMPENGARUHI PERILAKU PENGGUNAAN ALAT PELINDUNG DIRI (APD) PADA PEKERJA PERKEBUNAN SAWIT PT. KEDATON MULIA PRIMAS JAMBI TAHUN 2017
}

\author{
Melda Yenni \\ Sekolah Tinggi Kesehatan Harapan Ibu Jambi \\ E-mail: Meldayenni74@gmail.com
}

\begin{abstract}
The increasing of growth of any oil palm crop is not accompanied by safe behavior in the use of PPE in oil palm plantations. This is evident from most workers who do not work safely by not using PPE when they accomplished their activities. This study aims to determine of the use of Personal Protective Equipment (PPE) to workers in oil palm plantations. This is a quantitative research with cross sectional.The study population was all plantation workers totaling 77 workers and the sampling technique using total sampling method from the total total population of 77 workers. The results showed that the behavior of using PPE was in the bad category at $61.0 \%$. Knowledge $(p=0.031)$, attitude $(p=0.001)$ and training $(0.018)$ are variables that have a relationship with the use of PPE. Conclusions show that most workers know about the use of PPE but workers do not believe that one way to reduce the risk of workplace accidents is by using personal protective equipment and most of them have said that they have attended training in the use of personal protective equipment.
\end{abstract}

Keywords : Behavior in using PPE; Oil Palm Plantation; Workers Plantation.

\begin{abstract}
ABSTRAK
Meningkatnya pertumbuhan perkebunan kelapa sawit tidak diiringi dengan perilaku aman dalam penggunaan APD diperkebunan sawit. Hal ini terlihat dari sebagian besar pekerja belum bekerja secara aman dengan tidak menggunakan APD saat melakukan aktivitasnya. Penelitian ini bertujuan untuk mengetahui perilaku penggunaan alat pelindung diri (APD) pada pekerja perkebunan kelapa sawit PT.Kedaton Mulia Primas Jambi.Penelitian menggunakan metode cross sectional. Populasi penelitian adalah seluruh pekerja perkebunan yang berjumlah 77 pekerja dan teknik pengambilan sampling dengan menggunakan metode total sampling dari seluruh total populasi yang berjumlah 77 pekerja. Hasil penelitian menunjukan perilaku penggunaan APD kategori buruk sebesar $61,0 \%$. Pengetahuan $(p=0,031)$, sikap $(p=0,001)$ dan pelatihan $(0,018)$ merupakan variabel yang memiliki hubungan dengan penggunaan APD. Sebagian besar pekerja mengetahui tentang pemakaian APD tetapi pekerja kurang mempercayai bahwa bahwa satu cara untuk
\end{abstract}

Cara mengutip: Yenni, Melda. (2020). Fakto-faktor yang Mempengaruhi Perilaku Penggunaan Alat Pelindung Diri (APD) Pada Pekerja Perkebunan Sawit PT. Kedaton Mulia Primas Jambi Tahun 2017. Care:Jurnal Ilmiah Ilmu Kesehatan, 8(1), 84-91 
mengurangi risiko kecelakan kerja yaitu dengan menggunakan alat pelindung diri dan sebagian besar menyatakan sudah pernah mengikuti pelatihan dalam pemakaian alat pelindung diri.

Kata Kunci : Perilaku Penggunaan APD; Pekerja; Perkebunan Sawit.

\section{PENDAHULUAN}

Penerapan safety di perkebunan kelapa sawit tidak mudah diterapkan karena tenaga kerja terutama pekerja lapangan memiliki tingkat pendidikan yang rendah. Sulit untuk menerapkan budaya safety atau keselamatan kerja yang aman. Pekerja lapangan selalu berhubungan dengan alatalat kerja yang tajam seperti parang, cangkul, dodos dan bahan-bahan kimia baik pestisida serta pupuk.

Berdasarkan ILO data pada tahun 2015, setiap hari terjadi sekitar 6.000 kecelakaan kerja yang mengakibatkan korban fatal di dunia, sedangkan di Indonesia terdapat 20 kasus kecelakaan kerja yang dialami para buruh dari setiap 100 ribu tenaga kerja((ILO), 2017). Angka kecelakaan kerja di Indonesia masih tinggi. Data Badan Penyelenggara Jaminan Sosial (BPJS) Ketenagakerjaan, hingga akhir 2015 telah terjadi kecelakaan kerja sebanyak $\quad 105.182 \quad$ kasus(BPJS Ketenagakerjaan, 2016). Dalam proses pembentukan dan perubahan perilaku manusia terdapat faktor-faktor yang berpengaruh, diantaranya factor dari dalam (internal) seperti susunan syaraf pusat, persepsi, motivasi, proses belajar, dan sebagainya. Sedangkan faktor yang berasal dari luar (eksternal) seperti lingkungan fisik/non fisik, iklim, manusia social, dan ekonomi, kebudayaan, dan sebagainya (Notoatmodjo S, 2007)

Alat Pelindung Diri (APD) merupakan alat yang digunakan untuk melindungi baik sebagian maupun seluruh tubuh pekerja dari paparan potensi bahaya yang ada dilingkungan kerja yang mengakibatkan kecelakan dan penyakit akibat kerja.. Secara teknis pelindung diri tidaklah dapat melindungi tubuh secara sempurna terhadap potensi bahaya,namun demikian tingkat kepararan dari kemungkinan terjadinya kecelakaan dan penyakit akibat kerja dapat dikurangi dengan mengunakan alat pelindung diri. Dengan demikian, dapat ditegaskan bahwa meskipun telah menggunakan alat pelindung diri, tetapi upaya pencegahan dan pengendalian resiko kecelakaan secara teknis dan teknologi meruapakan langkah utama untuk menekan kecelakaan kerja (Tarwaka, 2008) 
Seorang pekerja tidak menggunakan alat pelindung diri dikarenakan tidak nyaman (risih, panas, berat dan tergangu) maka kesadaran akan manfaat alat pelindung diri bagi pekerja ditingkatkan dengan cara melakukan pembinaan secara terus menerus dan memberikan pelatihan. Pembinaan yang terus menerus dapat meningkatkan kesadaran dan wawasan mereka. Salah satu cara yang efektif adalah melalui pelatihan. Peningkatan pengetahuan dan wawasan akan menyadarkan tentang pentingnya penggunaan alat pelindung diri (APD). Perlu adanya Komitmen yang baik tentang keselamatan dan kesehatan kerja baik dari pihak perusahaan, manajemen maupun pekerja sehingga pekerja patuh dalam dalam pemakaian alat pelindung diri. Kepatuhan (Compliance) adalah salah satu bentuk dari tindakan seseorang yang dipengaruhi oleh faktor internal dan eksternal. kepatuhan pemakaian alat pelindung diri biasanya disebut juga dengan ketaatan dalam pemakaian alat pelindung diri (Tarwaka, 2008).

PT. Kedaton Mulia Primas Jambi merupakan salahsatu perusahaan besar di Jambi yang bekerja dalam bidang perkebunan sawit, banyak sekali jenis aktifitas pekerja yang dapat menimbulkan kecelakaan kerja, seperti tertimpa buah ketika pemanenan, pembersihan perkebunan, terkena duri saat pemanenan, keracunan saatmelakukan penyemprotan dan masih banyak jenis aktifitas yang beresiko mengancam keselamatan pekerja. Akan tetapi timbulnya kecelakaan dapat dicegah, asalkan pekerja mau berperilaku aman dengan menggunakan alat pelindung diri secara benar lengkap saat bekerja.

\section{METODE PENELITIAN}

Penelitian ini merupakan penelitian analitik pendekatan kuantitatif dengan metode cross sectional yang bertujuan untuk mengetahui gambaran perilaku penggunaan alat pelindung diri serta hubungananya dengan pengetahuan, sikap dan pelatihan. Analisis data penelitian ini menggunakan Univariat dan Bivariat. Instrumen pengambilan data yang digunakan dengan menggunakan kuesioner dan observasi dilapangan. Penelitian ini dilaksanakan pada bulan Agustus tahun 2017. Populasi penelitian adalah seluruh pekerja di perkebunan sawit PT. Kedaton Mulia Primas yang berjumlah 77 orang. Cara pengambilan sampel penelitian ini dengan menggunakan teknik total sampling dengan jumlah sampel pada penelitian ini sebanyak 77 orang dari seluruh populasi. Adapun variabel yang diteliti yaitu variabel independen yaitu pengetahuan, sikap, 
pelatihan dan keyakinan dan variabel dependent yaitu perilaku pemakaian APD.

\section{HASIL}

Tabel 1. Distribusi Frekuensi Perilaku Pemakaian APD

\begin{tabular}{lll}
\hline Variabel & f & $\mathbf{( \% )}$ \\
\hline Perilaku & & \\
Baik & 30 & 39,0 \\
Kurang Baik & 47 & 61,0 \\
Pengetahuan & & \\
Tinggi & 26 & 33,8 \\
Rendah & 51 & 66,2 \\
Sikap & & \\
Positif & 36 & 46,8 \\
Negatif & 41 & 53,2 \\
Pelatihan & & \\
Pernah & 21 & 27,3 \\
Tidak pernah & 56 & 72,7 \\
\hline
\end{tabular}

Berdasarkan Tabel 1 menunjukan bahwa sebanyak $61,0 \%$ pekerja memiliki perilaku kurang baik dalam pemakaian Alat Pelindung Diri, sebanyak 66,2\% pekerja memiliki pengetahuan yang rendah dalam pemakaian Alat Pelindung Diri, sebanyak $53,2 \%$ pekerja memiliki sikap yang negatif dalam pemakaian Alat Pelindung Diri, sebanyak $72,7 \%$ pekerja menyatakan tidak pernah mengikuti pelatihan dalam pemakaian APD

Berdasarkan Tabel 2 menunjukan bahwa pekerja dengan yang mempunyai pengetahuan rendah mempunyai perilaku buruk sebesar 36(85,7\%) dalam pemakaian APD, pekerja yang mempunyai sikap negatif mepunyai perilaku buruk sebesar $33(78,6 \%)$ dalam pemakain APD, dan pekerja yang tidak pernah mengikuti pelatihan penggunaan APD mempunyai perilaku buruk dalam pemakian APD sebesar 39 (69,6\%). Hasil uji statistik terdapat hubungan antara pengetahuan $(P-V$ alue $=0,031)$, sikap $(\mathrm{P}$ Value $=0,001)$, pelatihan $(\mathrm{P}-$ Value $=$ 0,018) dengan perilaku pemakaian APD.

Tabel 2. Hubungan Pengetahuan, sikap, pelatihan pekerja dengan Perilaku Pemakaian APD di PT. Kedaton Mulia Primas Jambi Tahun 2017

\begin{tabular}{|c|c|c|c|c|c|}
\hline \multirow{3}{*}{ Variabel } & \multicolumn{4}{|c|}{ Perilaku Pekerja } & \multirow{3}{*}{$\begin{array}{l}P- \\
\text { value }\end{array}$} \\
\hline & \multicolumn{2}{|c|}{ Buruk } & \multicolumn{2}{|c|}{ Baik } & \\
\hline & $\mathrm{f}$ & $(\%)$ & $f$ & $(\%)$ & \\
\hline \multicolumn{6}{|l|}{ Pengetahuan } \\
\hline Tinggi & 11 & 31,4 & 24 & 68,6 & 0,031 \\
\hline Rendah & 36 & 85,7 & 6 & 14,3 & \\
\hline \multicolumn{6}{|l|}{ Sikap } \\
\hline Positif & 14 & 40 & 21 & 60 & 0,001 \\
\hline Negatif & 33 & 78,6 & 9 & 21,4 & \\
\hline \multicolumn{6}{|l|}{ Pelatihan } \\
\hline Pernah & 8 & 38,1 & 13 & 61,9 & 0,018 \\
\hline Tidak Pernah & 39 & 69,6 & 17 & 30,4 & \\
\hline
\end{tabular}

\section{PEMBAHASAN}

Berdasarkan hasil analisa tentang perilaku pekerja menunjukan kurangnya kesadaran dari diri pekerja tentang pentingnya dalam pemakaian APD, adanya perasaan yang tidak nyaman, perasaan risih, berat dan terganggu jika menggunakan alat pelindung diri ditempat kerja. Untuk meningkatkan kesadaran diri dari pekerja perlu adanya pembinaan yang terus menerus agar timbul kesadaran dan wawasan dari para pekerja, salah satu cara 
yang efektif adalah melalui pelatihan untuk memperkecil kemungkinan terjadinya kecelakaan dengan berperilaku aman ditempat kerja. Heinrich (1980) dalam Bird dan Germain (1990)(Bird, E.F \& Germani, 1990) menyatakan dengan perilaku atau tindakan aman memperkecil kemungkinan terjadinya kecelakaan ditempat kerja. Dengan perilaku hidup sehat kita sudah berupaya untuk mempertahankan kesehatan tubuh(Tarwaka, 2008).

Hasil penelitian Pengetahuan Pekerja terhadap Penggunaan Alat Pelindung Diri menunjukan bahwa sebagian besar pekerja mengetahui tentang pemakaian APD. Sejalan dengan penelitianEdiana D, Meidika A H, 2017)yang menyatakan bahwa terdapat hubungan yang bermakna antara faktor pengetahuan terhadap pemakaian alat pelindung diri pada petani jeruk (Ediana \& Meidika, 2017).

Baik buruknya atau tinggi rendahnya pengetahuan seseorang tergantung dari sumber informasi yang tersedia baik dalam bentuk penyuluhan kesehatan dan media (Notoatmodjo S, 2007). Semakin luas pengetahuan seseorang maka semakin positif perilaku yang dilakukannya (Widiyatun \& Rusmi, 1999). Pengetahuan yang meningkat tidak selalu menyebabkan perubahan perilaku seseorang bertindak sesuai dengan pengetahuannya (Notoatmodjo S, 2007). Menurut peneliti karena pengetahuan merupakan dasar sehingga orang bertindak, bila tingkat pengetahuan pekerja tinggi mengenai APD maka pekerja tersebut akan memanfaatkan alat pelindung diri dengan sebaiknya, namun bila pengetahuan pekerja tentang manfaat penggunaan alat pelindung diri rendah maka pekerja tersebut tidak akan mau memanfaatkan alat pelindung diri yang telah disediakan. Upaya yang harus dilakukan agar pekerja mempunyai pengetahuan mengenai APD dengan memberi selalu sosialisasi, workshop, penyuluhan, morning talk kepada pekerja tentang cara pemakaian, pemeliharaan dan penyimpanan agar pekerja tidak lagi menganggap APD sesuatu yang tidak penting dan mengganggu pekerja.

Hasil penelitian sikap pekerja terhadap Penggunaan Alat Pelindung Dirimenunjukan bahwa sebagian besar pekerja bersikap tidak baik terhadap pemakaian alat pelindung diri dan menganggap APD menjadi penghalang dalam bekerja. Hal ini sesuai dengan hasil observasi peneliti bahwa pekerja bersikap tidak baik atau buruk dalam pemakaian 
alat pelindung diri walaupun sudah ada aturan yang diberikan.

Sikap adalah predisposisi untuk melakukan atau tidak melakukan suatu perilaku tertentu, tetapi sikap lebih merupakan proses kesadaran yang sifatnya individual, artinya hanya individu yang bisa mengendalikan dan mempertahankan sikap masing-masingnya. Sikap dapat bersifat positif dan negatif sehingga sikap pekerja dalam pemakaian APD ini hanya pekerja itu sendiri yang bisa merubahnya (Notoatmodjo S, 2007). Selain alasan diatas ada alasan lain yang menimbulkan sikap negatif karena pekerja kurang mempercayai bahwa bahwa alat pelindung diri tersebut merupakan salah satu untuk mengurangi terjadinya risiko kecelakaan kerja. Disamping itu juga mungkin kurangnya informasi atau sosialisasi yang jelas tentang penggunaan alat pelindung diri yang tidak mampu membentuk sikap yang positif bagi pekerja. Pekerja beranggapan bahwa tanpa alat pelindung diri pun mereka dapat melakukan pekerjaannya, keadaan yang demikian itu merugikan pekerja dalam melakukan aktivitasnya dan tidak memberikan perilaku aman dalam bekerja. Upaya untuk mengatasi sikap pekerja itu dengan memberi kemantapan dan keyakinan kepada pekerja melalui penyuluhan bahwa dengan pemakaian APD dapat mengurangi risiko kecelakaan kerja dan penyakit akibat kerja.

Hasil analisa pelatihan pekerja terhadap Pemakaian Alat Pelindung Dirimenunjukan bahwa sebagian besar menyatakan sudah pernah mengikuti pelatihan dalam pemakaian alat pelindung diri. Sejalan dengan penelitian yang dilakukanRaodhah \&Gemely (2014) yang menyatakan bahwa ada hubungan antara pelatihan K3 dengan pemakaian APD pada karyawan bagian packer PT. Semen Bosowa Maros(Raodhah S, 2014). Hasil penelitian ini sesuai dengan yang dikemukakan oleh Straus dan Sayles pelatihan berarti merubah perilaku. Pelatihan adalah salah satu bentuk proses pendidikan dengan melalui training sasaran belajar atau sasaran pendidikan yang akan memperoleh pangalaman belajar yang akhirnya akan menimbulkan perubahan perilaku(Notoatmodjo S, 2007).

Dengan adanya pelatihan pekerja memperoleh pengalaman dalam pemakaian APD, tahu akan manfaat dan kegunaan APD. Upaya ini berguna untuk mempromosikan kesalamatan ditempat kerja dengan memberikan orientasi pelatihan bagi pekerja baru. Pelatihan 
untuk pembentukan pengetahuan yang baru, guna memperbaharui pengetahuan yang sudah ada. Pelatihan memberikan manfaat ganda dalam promosi keselamatan. Pelatihan dimaksudkan untuk meningkatkan pemahaman kerja terhadap hazard dan risiko. Dengan adanya peningkatan kesadaran terhadap risiko, pekerja dapat menghindari kondisi tertentudengan mengenali pajanan dan memodifikasinya dengan mengubah prosedur kerja menjadi lebih aman

Pelatihan K3 dapat dilakukan melalui koordinasi dengan pihak-pihak terkait seperti pihak swasta, maupun dari disnaker sendiri. Latihan keselamatan adalah penting mengingat kebanyakan kecelakaan terjadi pada pekerja baru yang belum terbiasa bekerja dengan selamat. Pentingnya segi keselamatan harus ditekankan kepada tenaga kerja oleh pelatih, pimpinan kelompok atau instruktur tetapi yang terpenting pelatihan itu diberikan secara rutin oleh perusahaan sebagai tempat pekerja melakukan aktivitasnya.

\section{KESIMPULAN}

Dari hasil dan pembahasan penelitian yang dilaksanakan di Perkebunan Sawit PT. Kedaton Mulia Primas Jambi Tahun 2017, tentang perilaku pemakaian alat pelindung diri (APD), dapat ditarik beberapa kesimpulan, bahwa perilaku pekerja menunjukan kurangnya kesadaran dari diri pekerja dalam pemakaian APD, Terdapat hubungan yang signifikan antara pengetahuan, sikapdan pelatihan terhadap perilaku pekerja dalam pemakaian APD.

\section{SARAN}

Bagi perusahaan, Perlunya komitmen yang kuat dari pihak perusahaan dengan merubah pandangan pengusaha dengan mengefektifkan unit keselamatan dan kesehatan kerja guna dalam meningkatkan pengetahuan pekerja mengenai APD dengan memberi berbagai kegiatan seperti workshop, penyuluhan, morning talk terusmenerus dan mendukung upaya pemakaian APD dengan menunjukan keteladanan yang baik.Memberi kemantapan kepada pekerja dari bersikap negatif terhadap pemakaian APD sampai bersikap positif.Memberi pelatihan secara terus menerus sampai timbunya kesadaran pekerja dalam pemakaian APD. Memberikan penegasan dan peningkatan terhadap aturan atau SOP yang telah ada dan memperbaharui peraturan disesuaikan dengan keadaan zaman dalam hal pemakaian APD. 


\section{UCAPAN TERIMA KASIH}

Ucapan terima kasih Saya ucapkan sebagai penulis atas seluruh partisipasi semua pihak yang telah membantu dalam penyelesaian penelitian ini. Terutama kepada pihak STIKES Harapan Ibu yang telah memberikan bantuan dana sehingga terselesainya penelitian ini.

\section{REFERENSI}

Bird, E.F \& Germani, G. . (1990). Practical Loss Control Leadership, Edisi Revisi. USA.

BPJS Ketenagakerjaan. (2016). Angka Kasus Kecelakaan Kerja.

Ediana, D., \& Meidika. (2017). Hubungan Kenyamanan, Pengetahuan dan Sikap
Petani dengan Penggunaan Alat Pelindung Diri Pestisida pada Petani Jeruk. Jurnal Human Care, 2(3).

(ILO), I. L. O. (2017). Keselamatan dan Kesehatan Kerja. Jakarta: International Labour Organization.

Notoatmodjo S. (2007). Ilmu Perilaku Kesehatan. Rineka Cipta . Jakarta.

Raodhah S, G. D. (2014). Faktor-Faktor Yang Berhubungan Dengan Penggunaan Alat Pelindung Diri Pada Karyawan Bagian Packer PT Semen Bosowa Maros Tahun 2014. Public Health Science Journal.

Tarwaka. (2008). Keselamatan Dan Kesehatan Kerja"Manajemen dan Inplementasi K3 diTempat Kerja. Harapan Press. Surakarta.

Widiyatun, \& Rusmi. (1999). Ilmu Perilaku "Buku Pegangan Mahasiswa." Jakarta: CV. Sagung Seto. 